Ulrike Einhorn-Stoll, Hanna Kastner, Stephan Drusch

\title{
Thermally induced degradation of citrus pectins during storage - Alterations in molecular structure, colour and thermal analysis
}

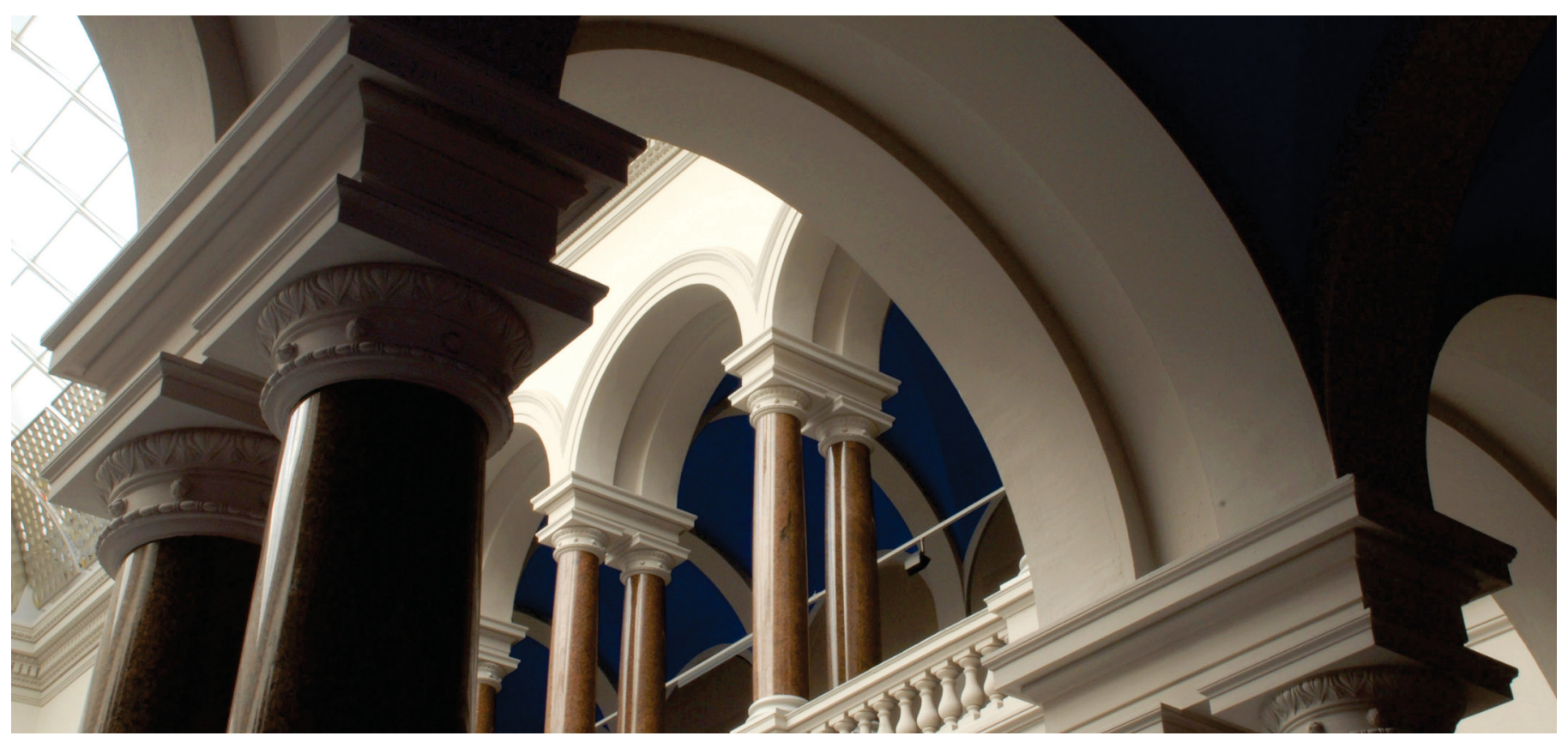

Einhorn-Stoll, U., Kastner, H., \& Drusch, S. (2014). Thermally induced degradation of citrus pectins during storage - Alterations in molecular structure, colour and thermal analysis. Food Hydrocolloids, 35, 565-575. https://doi.org/10.1016/j.foodhyd.2013.07.020 


\title{
Thermally induced degradation of citrus pectins during storage - Alterations in molecular structure, colour and thermal analysis
}

\author{
U. Einhorn-Stoll, H. Kastner, S. Drusch
}

Technische Universität Berlin, Food Technology and Food Material Science, Königin-Luise-Strasse 22, D-14195 Berlin, Germany

\section{Abstract}

Commercial citrus pectins (17 samples from 3 different suppliers) were stored at $60{ }^{\circ} \mathrm{C}$ and $80 \%$ humidity for two weeks. Molecular parameters (galacturonan content, degree of methoxylation, intrinsic viscosity), colour and behaviour in thermal analysis (DSC and TG) were tested and the results were compared with those of model pectins prepared under laboratory conditions from a previous study. Whereas the molecular parameters and colour of both groups changed similarly, considerable differences in the thermal analysis were found not only between model pectins and commercial pectins but also between commercial samples from different suppliers. It seems that varying processing conditions between laboratory preparation and industrial processing as well as differences in industrial scale processing influence the pectin properties and their degradation during storage.

All commercial citrus pectin samples were strongly demethoxylated and depolymerised, former high-methoxylated pectins with degree of methoxylation $(\mathrm{DM})>50 \%$ became low-methoxylated with $\mathrm{DM}<50 \%$ and some low-methoxylated samples afterwards had a DM close to pectic acid. As a result, also their gelation properties changed markedly. For pectin producing and applying companies it might be essential to check the properties of pectins after longer storage under unfavourable conditions. As a consequence, a variation of the gelation conditions for pectins after storage might be necessary. 
Pectins are branched heteropolysaccharides with a backbone of galacturonic acid and rhamnose molecules, side chains of neutral sugars are linked to rhamnose. The structure of pectins is well described and discussed in several review papers (Schols \& Voragen, 2002; Lopes da Silva \& Rao, 2006; Thakur, Singh, \& Handa, 1997; Voragen, Pilnik, Thibault, Axelos, \& Renard, 1995) and other publications (Rolin, Chrestensen, Hansen, Staunstrup, \& Sorensen, 2010; Schols, Coenen, \& Voragen, 2009; Vincken et al., 2003).

The process for the production of high-methoxylated citrus pectin (HMP) is well standardised and similar for different pectin suppliers. The companies adapt their products to special applications such as gelling and thickening agents using limited demethoxylation by enzymes or acids as well as amidation by ethanolic ammonia (Rolin, 2002; Rolin et al., 2010). The processing for the production of low-methoxylated pectins (LMP) or amidated pectin (LMP-AMID) can differ stronger from company to company, for instance with respect to the enzymes used, the temperature, time or $\mathrm{pH}$ for demethoxylation.

Pectins can be characterised by different molecular parameters; the most important is the degree of methoxylation (DM). It describes the percentage of methoxylated $\mathrm{C}_{6}$ atoms in the galacturonic acid backbone and strongly determines the gelling properties. The second important molecular parameter is the molecular weight. It is often characterised through the intrinsic viscosity (IV), which is governed mainly by the chain length. The third important molecular parameter, the galacturonan content (GC), indicates the purity of the pectin. Pectins of comparable molecular parameters do not necessarily have comparable material and techno-functional properties, too. Recent works (Einhorn-Stoll, Kastner \& Senge, 2012, Kastner, Einhorn-Stoll \& Senge, 2012a) compared molecular, material and techno-functional properties of commercial citrus pectins and showed that samples with comparable molecular parameters significantly differed in colour, particle size and surface morphology as well as in their behaviour during thermal analysis (start of thermal degradation, sample homogeneity) and gelation behaviour. The authors concluded that these differences resulted from variations in pectin sources and processing conditions.

In addition to the differences resulting from varying raw materials and processing conditions, the molecular parameters may undergo further changes during storage. Pectins are delivered from producers to food companies in big packages and stored there until use. The time of storage and the conditions can vary considerably, especially with respect to temperature and humidity. Only very limited studies on the effect of storage on molecular parameters and techno-functionality of pectins exist. An early study from Padival, Ranganna and Manjrekar (1981) described alterations of dry model pectins, prepared on lab scale, during storage. These authors found pectin degradation and alterations in gelation and solubility after long term storage at room temperature for several months. 
Recently, the research group of the present study published results on changes occurring during storage of pectins, prepared in laboratory at well-defined conditions. These samples were stored at temperatures above $50{ }^{\circ} \mathrm{C}$ and humidity above $65 \%$ for two weeks (Einhorn-Stoll \& Kunzek, 2009a). Changes in molecular parameters included demethoxylation, depolymerisation and formation of brown reaction products. The extent of these changes increased with increasing temperature and relative humidity, but not to a similar extent for all pectins. Demethoxylation was the dominating reaction and was associated with other changes such as browning and behaviour in thermal analysis. In addition, depolymerisation occurred to an unexpectedly high extent. The typical cleavage reactions of pectins in solution are acidic hydrolysis as discussed by Diaz, Anthon, and Barrett (2007) or Fraeye et al. (2007) and b-elimination as described for instance by Keijbets and Pilnik (1974), Kravtchenko, Arnould, Voragen and Pilnik (1992) or Krall and McFeeters (1998). They could, however, not sufficiently explain these results. The well-known ß-elimination requires the presence of methoxyl groups close to the reacting glycosidic linkages, which are only sparingly available in low methoxylated pectins. An acidic hydrolysis requires a high water activity and only limited amounts of unsaturated oligogalacturonides, which cause brown colour (Voragen, Schols \& Pilnik, 1988, Ibarz, Garza, \& Pagan, 2008), are formed. Thus, that reaction does not sufficiently explain the strong browning of the stored samples. Therefore, an additional cleaving mechanism was proposed (Einhorn-Stoll \& Kunzek, 2009a) that would result in an increased number of unsaturated oligogalactoronides and possibly more and/or other browning components. However, the detailed reactions occurring and the structure of the final reaction products are not elucidated, yet.

The effects of storage on the model pectin degradation were tested by thermal analysis (TA) as combined DSC and TG. This method has been successfully used for the characterisation of pectins (Einhorn-Stoll, Kunzek \& Dongowski, 2007, Einhorn-Stoll \& Kunzek, 2009b). The main information from TA for pectin studies are the shape of the DSC curves, the shift of the DSC and DTG curves (to the left $=$ sample is more thermal sensible, to the right = more stable), the peak width $(P W)$ of the DTG curve (broader peak = less homogenous sample) and the maximum degradation velocity $\left(v_{\max }\right) . v_{\max }$ is the maximum height of the DTG peak and often correlates with the peak width; the more homogenous the sample (narrow peak) the more rapid it degrades and the higher is $v_{\max }$. TA thus allows a relatively quick screening for structural alterations resulting from pectin modifications. In the cited studies, the typical exothermic degradation peak for stored pectins was shifted to the left (reduced thermal stability) and, in samples treated under acidic conditions, an endothermic prepeak was reduced after storage. The extent of all these changes depended on the type (acidic, alkaline, mechanolytical) and extent of the pectin modification procedures.

To the best of the authors' knowledge, no systematic examination of the effects of storage on changes in the properties of commercial pectins has been performed until now. It is expected that 
due to differences in pectin sources and processing conditions as outlined above, even more severe changes in molecular parameters and techno-functional properties occur under adverse conditions during storage. Therefore, it is the intention of the presented paper to investigate whether the changes found in pectins prepared on lab scale also occur in commercial pectins. For this purpose, 12 pectins from different suppliers, examined in detail before (Einhorn-Stoll et al., 2012), and 5 additional citrus pectins were stored and tested for alterations in molecular parameters, surface morphology, and colour as well as behaviour in thermal analysis. Gel formation of selected samples was analysed by oscillation measurements to characterise the technological functionality. Moreover, different analytical methods (chemical analysis, colour measurement, thermal analysis, and FT-IR spectroscopy) were evaluated for their potential to be used as screening method in routine control in the food industry. 


\section{$2 \quad$ Materials and methods}

\subsection{Materials}

Four types of commercial citrus pectins from three different suppliers were used: eight highmethoxylated pectins (HMP), three low-methoxylated pectins with acidic treatment (LMP-AC), four low-methoxylated pectins with enzymatic treatment (LMP-ENZ) and two amidated pectins (LMP-AMID), details in Table 1. All 17 pectins were not standardised by blending with other sugars.

Table 1 Molecular parameters, colour and results of thermal analysis of original pectins. HMP = high-methoxylated pectin, $L M P-A C=$ acidic treated low-methoxylated pectin, $L M P-E N Z=$ enzymatic treated $L M P, L M P-A M I D=$ amidated pectin, $G C=$ galacturonan content, $D M=$ degree of methoxylation, $I V=$ intrinsic viscosity, $L=$ lightness, $+a=r e d$ colour, $+b=$ yellow colour, $D S C=$ differential scanning calorimetry, $D T G=$ differential thermogravimetry, $T_{p}=$ peak temperature, $P W=$ peak width, $n_{\max }=$ maximum degradation velocity .

\begin{tabular}{|c|c|c|c|c|c|c|c|c|c|c|c|}
\hline \multirow[t]{2}{*}{ Sample } & \multirow[t]{2}{*}{ Type } & \multicolumn{3}{|c|}{ Molecular parameters } & \multicolumn{3}{|l|}{ Colour } & \multicolumn{4}{|c|}{ Thermal analysis } \\
\hline & & $\begin{array}{l}\text { GC } \\
(\%)\end{array}$ & $\begin{array}{l}\text { DM } \\
(\%)\end{array}$ & $\begin{array}{c}\text { IV } \\
\left(\mathrm{cm}^{3} / \mathrm{g}\right)\end{array}$ & $\mathbf{L}$ & a & b & $\begin{array}{c}T_{p \text { DSC }} \\
\left({ }^{\circ} \mathrm{C}\right)\end{array}$ & $\begin{array}{l}T_{\mathrm{p} \mathrm{DTG}} \\
\left({ }^{\circ} \mathrm{C}\right)\end{array}$ & $\begin{array}{l}\text { PW } \\
(\mathrm{K})\end{array}$ & $\begin{array}{c}v_{\max } \\
(\% / \text { min })\end{array}$ \\
\hline $1 \mathrm{~A}$ & HMP & 89.3 & 60.9 & 639 & 88.60 & 1.09 & 12.86 & 240.5 & 237.8 & 27.6 & 19.9 \\
\hline 1B & HMP & 85.5 & 59.6 & 598 & 89.67 & 1.06 & 10.85 & 239.4 & 236.1 & 25.8 & 22.2 \\
\hline $2 A$ & HMP & 81.6 & 68.9 & 647 & 86.40 & 2.00 & 12.20 & 244.0 & 240.3 & 35.6 & 16.3 \\
\hline 2B & HMP & 87.7 & 55.1 & 492 & 87.70 & 1.60 & 11.40 & 245.0 & 240.7 & 34.5 & 16.2 \\
\hline 2D & HMP & 65.8 & 76.9 & 660 & 86.85 & 1.75 & 11.52 & 247.6 & 243.3 & 30.7 & 18.5 \\
\hline $3 A$ & HMP & 80.9 & 69.8 & 554 & 89.90 & 1.40 & 11.00 & 249.8 & 246.1 & 24.3 & 22.2 \\
\hline 3B & HMP & 83.4 & 57.1 & 576 & 88.40 & 1.70 & 12.90 & 247.9 & 243.9 & 25.7 & 20.7 \\
\hline $3 C$ & HMP & 81.5 & 63.6 & 608 & 88.50 & 1.80 & 14.00 & 249.6 & 245.8 & 24.7 & 21.4 \\
\hline $1 \mathrm{C}$ & LMP-AC & 94.0 & 25.5 & 301 & 89.97 & 1.54 & 16.89 & 239.1 & 234.9 & 25.6 & 19.6 \\
\hline 1D & LMP-AC & 75.8 & 36.4 & 421 & 85.14 & 2.43 & 14.50 & 241.5 & 236.1 & 37.5 & 14.6 \\
\hline $2 \mathrm{C}$ & LMP-AC & 90.5 & 30.1 & 358 & 81.20 & 3.40 & 24.00 & 246.7 & 241.0 & 33.5 & 15.8 \\
\hline $2 E$ & LMP-ENZ & 67.6 & 31.7 & 500 & 83.44 & 2.12 & 12.23 & 235.5 & 232.6 & 24.4 & 19.6 \\
\hline 3D & LMP-ENZ & 84.8 & 32.8 & 363 & 87.70 & 1.10 & 13.00 & 230.9 & 228.4 & 29.3 & 17.2 \\
\hline $3 E$ & LMP-ENZ & 81.5 & 30.2 & 336 & 84.00 & 2.70 & 20.10 & 234.1 & 231.6 & 28.0 & 17.8 \\
\hline $3 F$ & LMP-ENZ & 78.5 & 27.7 & 327 & 86.90 & 1.50 & 15.00 & 233.9 & 231.4 & 28.2 & 15.6 \\
\hline $2 F$ & LMP-AMID & 61.3 & 29.6 & 450 & 84.35 & 2.11 & 12.71 & 242.9 & 239.0 & 27.5 & 16.9 \\
\hline $3 K$ & LMP-AMID & 68.4 & 32.2 & 382 & 89.04 & 1.34 & 13.53 & 238.3 & 235.7 & 24.8 & 17.2 \\
\hline
\end{tabular}

\subsection{Methods}

Pectin storage: Storage was performed as described in Einhorn-Stoll and Kunzek (2009a) in a climate chamber KBF 115 with a controlled humidity system (Binder $\mathrm{GmbH}$, Tuttlingen, Germany) at $60{ }^{\circ} \mathrm{C}$ and $80 \%$ relative humidity for two weeks. These conditions are extreme and far from typical storage. They were chosen in order to accelerate the degradation processes. They do not correspond to a special storage time under normal conditions (accelerated real shelf-life test) but 
considering van't Hoffs'rule, 2 weeks at $60^{\circ} \mathrm{C}$ should correspond to about eight months at $20^{\circ} \mathrm{C}$. The additional effect of high humidity might increase that time to about one year.

The pectin samples were filled into Petri dishes; the lid was kept slightly open by a distance holder. After one week the samples were stirred in order to achieve a more homogenous reaction. After incubation all pectins were stored at room temperature and at approximately 6 mbar in an evacuated desiccator containing $\mathrm{P}_{4} \mathrm{O}_{10}$ as a drying agent in order to minimise absorbed water and to bring the sample to a more stable state before analysis.

Pectin characterisation: The galacturonan content (GC) and degree of methoxylation (DM) were determined colorimatrically by the m-hydroxydiphenyl method (Blumenkrantz \& Asboe-Hansen, 1973, Ibarz, Pagan, Tribaldo \& Pagan, 2006) and the chromotropic acid method (Baeuerle, Otterbach, Gierschner \& Baumann, 1977), respectively. The intrinsic viscosity (IV) as a parameter depending on molecular weight was analysed by an Ubbelohde capillary viscosimeter as described by Einhorn-Stoll, Salazar, Jaafar and Kunzek (2001). For colour determination, the dry samples were examined before and after incubation with a Chromameter CR 300 (Minolta, Japan) using the CIELAB system.

Thermal Analysis: The simultaneous thermal analysis (differential scanning calorimetry DSC and thermogravimetry TG with its first derivation DTG) was carried out using a STA 409 C device (Netzsch, Selb, Germany) according to Gloyna and Kunzek (1998), using the same conditions as in Einhorn-Stoll and Kunzek (2009a, 2009b): a linear heating rate of $10 \mathrm{~K} / \mathrm{min}$ from 20 to $450{ }^{\circ} \mathrm{C}$, dynamic inert nitrogen atmosphere $(75 \mathrm{~mL} / \mathrm{min}), 85 \mu \mathrm{L}$ Pt crucibles without lid and an empty crucible as reference, sample weight was approximately $20 \mathrm{mg}$. All runs were performed at least in duplicate. The instrument was calibrated by a standard procedure and the extrapolated onset, peak and offset temperatures as well as the maximum degradation velocity $\left(v_{\max }\right)$ were calculated with the Netzsch software as shown in Einhorn-Stoll et al. (2007).

Scanning electron microscopy (SEM) was made at the central microscopy unit of the TU Berlin (ZELMI) using S-2700 scanning electron microscope (Hitachi, Japan). The micrographs give a qualitative impression of the powder particle size and of the surface properties of the pectin particles.

FT-IR spectroscopy was made using a Equinox 55 with ATR unit (Golden Gate) from Bruker Optik $\mathrm{GmbH}$ (Ettlingen, Gemany) in order to get information of changes in the ratio of carboxyl and methoxyl groups that form two characteristic peaks at $1750 \mathrm{~cm}^{-1}$ for the ester group and $1630 \mathrm{~cm}^{-1}$ for the free carboxylic group (Hunter, Thomas, de Haseth \& Wicker, 2006, Lima, Paiva, Andrade \& Paixao, 2010, Panchev, Slavov, Nikolova \& Kratchanov, 2012). A decrease of the former and increase of the latter peak indicates demethoxylation. 
The gelling behaviour of the pectins was tested in high sugar gels (composition comparable to food applications) with temperature sweep using a rheometer Physica MCR 301 (Anton Paar, Germany). Oscillation measurements (temperature sweep) of storage modulus ( $\left.G^{\prime}\right)$ and loss modulus ( $\left.G^{\prime \prime}\right)$ were made using a profiled rotational cylinder CC27/P1 with Peltier cylinder temperature system TEZ 150P as described previously (Kastner, Einhorn-Stoll \& Senge, 2012a, 2012b). Typical structuring temperatures were calculated: At the initial structuring temperature (IST) the structure formation velocity ( $\mathrm{dG}^{\prime} / \mathrm{dt}$ ) starts to differ from 0 for the first time and the critical structuring temperature (CST) the velocity starts to increase strongly. Moreover, the gel point was determined as intersection of the $G^{\prime}$ and $G^{\prime \prime}$ curves. These parameters detect the liquid - solid transition and, thus, the pectin gel formation. 


\subsection{Changes in the molecular parameters after storage of the pectins}

The galacturonan content of all pectins increased during storage by up to $26 \%$ of the initial values (Table 2). This higher purity results from a degradation of neutral sugars after cleavage of their bonds to the rhamnogalacturonan backbone as well as cleavage within the neutral sugar side chains. The increase of the galacturonan content could be related neither to the type of pectin nor to the supplier, and thus to possible variations in the processing conditions.

Furthermore, the degree of methoxylation decreased during the storage period by 14 to $60 \%$ of the initial values (Table 2, Fig. 1). A demethoxylation has also been described for model pectins after thermal treatment (Einhorn-Stoll \& Kunzek, 2009a). Comparing the different types of LMP, acidic treated LMP were stronger demethoxylated than enzymatic treated or amidated pectins.

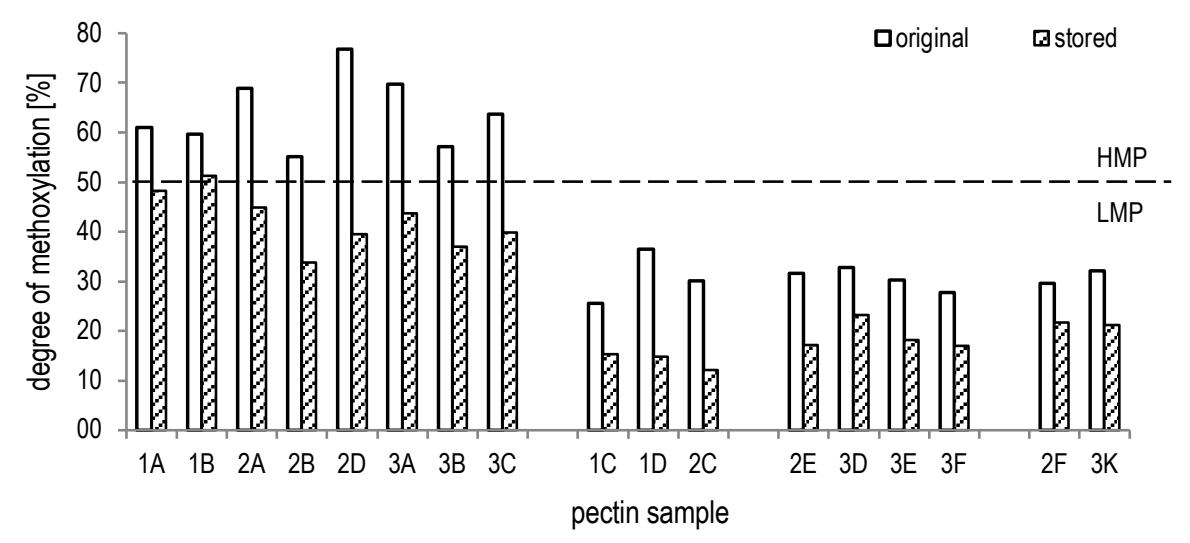

Fig. 1 Reduction of degree of methoxylation during pectin storage. The line at 50\% DM is the border of HMP and LMP.

As discussed above, the DM is crucial for the gelation mechanism as well as for the final properties of the gel, which differ considerably between HMP and LMP. Nearly all HMP with DM $>50 \%$ were demethoxylated to an extent, that they have to be classified as LMP with DM $<50 \%$ after storage (Fig. 1). Because of this strong decrease of the DM, an influence on the gelation process must be expected. Padival et al. (1981) described a similar effect of demethoxylation during storage on pectin gels by visual evaluation. Therefore, a test was made using one HMP (1A) and one LMP (1C), the results of the rheological measurements are shown in Fig. 2. 
Table 2 Molecular parameters, colour and results of thermal analysis of stored pectins. $S=$ stored pectin, HMP = high-methoxylated pectin, LMP-AC $=$ acidic treated lowmethoxylated pectin, $L M P-E N Z=$ enzymatic treated $L M P, L M P-A M I D=$ amidated pectin, GC = galacturonan content, DM = degree of methoxylation, $I V=$ intrinsic viscosity, $L=$ lightness, $+a=$ red colour, $+b=$ yellow colour, $D S C=$ differential scanning calorimetry, $D T G=$ differential thermogravimetry, Tp $=$ peak temperature, $P W$ $=$ peak width, $v_{\max }=$ maximum degradation velocity, $\Delta=$ difference stored - original pectin; $\uparrow / \downarrow=$ stored /original value $\bullet 100$

\begin{tabular}{|c|c|c|c|c|c|c|c|c|c|c|c|c|c|c|c|c|c|c|c|c|}
\hline \multirow[t]{2}{*}{ Sample } & \multicolumn{6}{|c|}{ Molecular parameters } & \multicolumn{6}{|c|}{ Colour } & \multicolumn{2}{|l|}{ DSC } & \multicolumn{6}{|l|}{ DTG } \\
\hline & $\begin{array}{c}\text { GC S } \\
(\%)\end{array}$ & $\begin{array}{c}\uparrow \mathrm{GC} \\
(\%)\end{array}$ & $\begin{array}{c}\text { DM S } \\
(\%)\end{array}$ & $\begin{array}{c}\downarrow \mathrm{DM} \\
(\%)\end{array}$ & $\begin{array}{c}\text { IV S } \\
\left(\mathrm{cm}^{3} / \mathrm{g}\right)\end{array}$ & $\begin{array}{l}\downarrow \text { IV } \\
(\%)\end{array}$ & LS & $\begin{array}{l}\downarrow L \\
\text { (\%) }\end{array}$ & a $S$ & $\begin{array}{l}\uparrow \mathbf{a} \\
(\%)\end{array}$ & b S & $\begin{array}{l}\uparrow \mathbf{b} \\
\text { (\%) }\end{array}$ & $\begin{array}{c}\mathrm{T}_{\mathrm{p} \mathrm{DSC}} \mathrm{S} \\
\left({ }^{\circ} \mathrm{C}\right)\end{array}$ & $\begin{array}{c}\Delta \mathrm{T}_{\mathrm{p} \mathrm{DSC}} \\
(\mathrm{K})\end{array}$ & $\begin{array}{r}T_{p ~ D T G} \\
\left({ }^{\circ} \mathrm{C}\right)\end{array}$ & $\begin{array}{c}\mathbf{S} \Delta \mathbf{T}_{\mathrm{p} \text { DTG }} \\
\text { (K) }\end{array}$ & $\begin{array}{c}\text { PW S } \\
\text { (K) }\end{array}$ & $\begin{array}{c}\Delta \mathrm{PW} \\
\text { (K) }\end{array}$ & $\begin{array}{c}v_{\max } S \\
(\% / m i n)\end{array}$ & $\begin{array}{c}\Delta v_{\max } \\
(\% / \min )\end{array}$ \\
\hline $1 \mathrm{~A}$ & 92.7 & 3.7 & 48.3 & 20.8 & 407 & 36.3 & 84.98 & 4.1 & 2.50 & 129.4 & 18.01 & 40.0 & 242.0 & 1.47 & 238.3 & 0.4 & 28.0 & 0.3 & 18.8 & 1.2 \\
\hline 1B & 93.2 & 9.0 & 51.2 & 14.1 & 398 & 33.4 & 87.86 & 2.0 & 1.61 & 51.9 & 14.72 & 35.7 & 241.5 & 2.15 & 238.0 & 1.9 & 26.7 & 0.9 & 20.7 & 1.4 \\
\hline $2 A$ & 86.9 & 6.6 & 44.9 & 34.8 & 316 & 51.2 & 84.14 & 2.6 & 2.78 & 39.0 & 16.88 & 38.4 & 243.4 & -0.60 & 239.4 & -0.9 & 29.8 & -5.8 & 18.5 & -2.2 \\
\hline 2B & 89.0 & 1.4 & 33.7 & 38.8 & 247 & 49.8 & 82.90 & 5.5 & 3.21 & 100.6 & 17.23 & 51.1 & 243.4 & -1.60 & 238.7 & -2.0 & 34.8 & 0.3 & 15.3 & 0.9 \\
\hline 2D & 82.7 & 25.6 & 39.6 & 48.5 & 348 & 47.3 & 80.32 & 7.5 & 3.25 & 85.7 & 20.44 & 77.4 & 245.8 & -1.80 & 241.6 & -1.7 & 28.6 & -2.1 & 18.3 & 0.2 \\
\hline $3 A$ & 87.6 & 8.2 & 43.7 & 37.4 & 260 & 53.1 & 82.37 & 8.4 & 3.43 & 145.0 & 19.13 & 73.9 & 242.1 & -7.75 & 238.1 & -8.0 & 27.6 & 3.3 & 20.3 & 1.9 \\
\hline $3 B$ & 90.2 & 8.1 & 37.0 & 35.3 & 266 & 53.8 & 82.38 & 6.8 & 3.39 & 99.4 & 18.73 & 45.2 & 240.4 & -7.45 & 236.2 & -7.8 & 30.6 & 5.0 & 17.8 & 2.9 \\
\hline $3 C$ & 89.3 & 9.5 & 39.9 & 37.3 & 270 & 55.6 & 80.57 & 9.0 & 3.94 & 118.9 & 20.55 & 46.8 & 241.1 & -8.50 & 237.1 & -8.8 & 28.6 & 4.0 & 19.0 & 2.5 \\
\hline $1 C$ & 99.9 & 6.3 & 15.4 & 39.7 & 180 & 40.2 & 72.86 & 19.0 & 3.23 & 109.7 & 17.22 & 2.0 & 238.4 & -0.70 & 233.8 & -1.2 & 28.5 & 3.0 & 17.3 & 2.3 \\
\hline 1D & 88.5 & 16.9 & 14.7 & 59.5 & 195 & 53.7 & 81.33 & 4.5 & 3.74 & 53.9 & 18.71 & 29.0 & 238.6 & -2.85 & 232.5 & -3.7 & 40.1 & 2.6 & 13.3 & 1.3 \\
\hline $2 C$ & 90.7 & 0.2 & 12.1 & 60.0 & 171 & 52.2 & 77.01 & 5.2 & 4.87 & 43.2 & 24.95 & 4.0 & 244.0 & -2.75 & 237.9 & -3.1 & 38.7 & 5.3 & 13.9 & 1.9 \\
\hline $2 E$ & 84.4 & 24.8 & 17.2 & 45.7 & 290 & 42.0 & 80.06 & 4.1 & 3.43 & 61.8 & 18.60 & 52.1 & 238.3 & 2.75 & 235.0 & 2.4 & 34.1 & 9.7 & 13.5 & 6.1 \\
\hline 3D & 85.9 & 1.2 & 23.3 & 29.0 & 287 & 20.9 & 82.71 & 5.7 & 2.83 & 157.3 & 18.24 & 40.3 & 234.9 & 4.00 & 232.4 & 3.9 & 32.8 & 3.5 & 14.6 & 2.7 \\
\hline $3 E$ & 90.7 & 11.3 & 18.2 & 39.9 & 255 & 24.1 & 77.30 & 8.0 & 4.89 & 81.1 & 23.95 & 19.2 & 237.8 & 3.70 & 235.0 & 3.4 & 32.7 & 4.8 & 12.9 & 5.0 \\
\hline $3 F$ & 86.4 & 10.1 & 17.1 & 38.4 & 216 & 34.0 & 81.86 & 5.8 & 3.11 & 107.3 & 18.50 & 23.3 & 237.8 & 3.85 & 235.3 & 3.9 & 30.6 & 2.4 & 13.0 & 2.6 \\
\hline $2 F$ & 68.6 & 12.0 & 21.7 & 26.7 & 323 & 28.2 & 76.74 & 9.0 & 4.11 & 94.8 & 19.0 & 49.8 & 242.1 & -0.77 & 238.2 & -0.8 & 25.7 & -1.9 & 17.3 & -0.4 \\
\hline $3 K$ & 75.9 & 11.0 & 21.1 & 34.4 & 223 & 41.6 & 75.48 & 15.2 & 4.45 & 232.1 & 20.97 & 55.0 & 239.9 & 1.65 & 236.7 & 1.0 & 34.8 & 10.0 & 13.2 & 3.9 \\
\hline
\end{tabular}



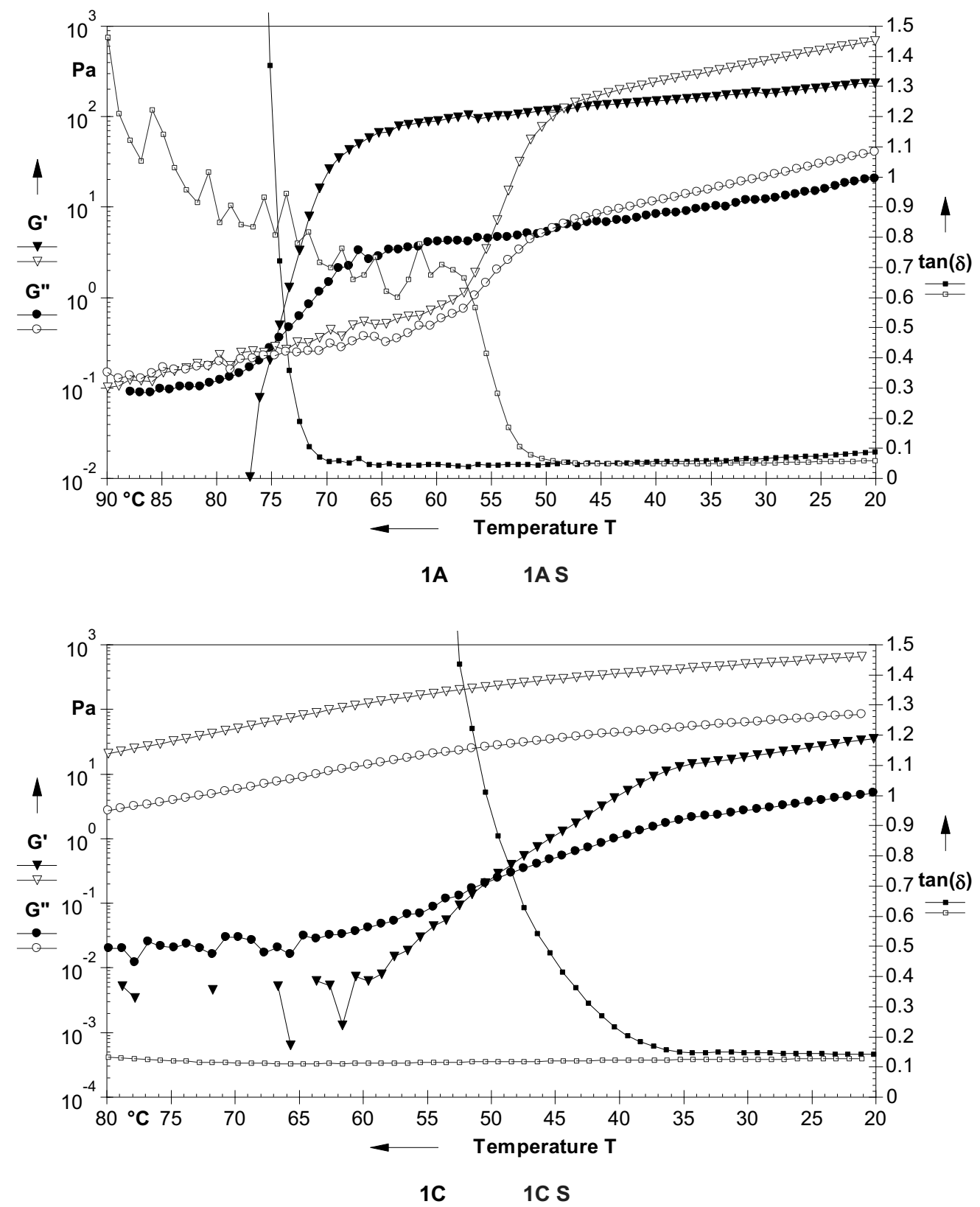

Fig. 2 Oscillation measurements of the gelling process of pectins; $a=H M P 1 A, b=L M P-A C 1 C$. Full symbols show untreated and open symbols show stored pectins.

Though the gel point of the HMP seemed to be similar before and after storage $\left(74\right.$ and $73^{\circ} \mathrm{C}$, Fig. 2a), the structure formation (first increase of dG0/dt) of the stored HMP started later (IST below $62{ }^{\circ} \mathrm{C}$ ) than that of the corresponding pectin sample before storage (IST below $72{ }^{\circ} \mathrm{C}$ ). This might be due to the reduced DM ( $48.3 \%$ is already a LMP) and/or because of changes in the material properties of the pectins during storage. In stored pectin samples inter- and intra- molecular interactions might have been formed, that need a certain rearrangement and longer solvatisation prior to gelation. In case of the LMP, the original sample formed a typical gel network with gel point as well as IST at $52{ }^{\circ} \mathrm{C}$. After storage the DM was reduced to only $15.4 \%$ and comparable to pectic acid. Though the rheological measurement showed a gel-like character ( $G^{\prime}>G^{\prime \prime}$, Fig. $\left.2 b\right)$, no gel 
point could be determined and no real network was formed; the final texture was similar to a weak gel, possibly with some pregelated structures.

The intrinsic viscosity $I V$, representing the molecular weight, decreased by $21-56 \%$ of the initial values (Table 2), partly because of the cleavage of the neutral sugar side chains but mainly because of the depolymerisation of the backbone. As previously discussed for the model pectins (Einhorn-Stoll \& Kunzek, 2009a), the typical depolymerisation reactions acidic hydrolysis and ß-elimination alone cannot sufficiently explain the depolymerisation especially of the LMP. Acid hydrolysis is possible only at a high water activity. Although moisture sorption occurs during storage at high relative humidity and water activity increases with temperature, water activity might not have been sufficiently high for this reaction. ß-elimination requires the presence of methoxyl groups close to the reacting glycosidic linkages, but these are limited in LMP. The additional cleaving mechanism, as proposed before (Einhorn-Stoll \& Kunzek, 2009a), can be assumed also for the commercial pectin degradation during storage.

In summary, the molecular parameters of the stored pectins changed in a similar way for all pectin samples, but to a different extent. A correlation between DM and IV before storage $\left(R^{2}=0.84\right)$ that has been reported for commercial pectin samples without storage (Einhorn-Stoll et al., 2012a) vanished after storage $\left(R^{2}=0.57\right)$. There were also no statistical significant correlations between the changes in the molecular parameters \% GC, \% DM and \% IV.

\subsection{FT-IR spectroscopy}

FT-IR spectroscopy was tested for its suitability as screening method of pectin alterations after storage. Changes in the spectrum should allow a relatively rapid detection of such alterations, especially the decrease of the degree of methoxylation. A broad survey of the FT-IR spectra of pectins is provided by Engelsen and Norgaard (1996), and Synytsya, Copikova, Matejka and Machovic (2003). Most important are two characteristic peaks at $1750 \mathrm{~cm}^{-1}$ for the ester group and $1630 \mathrm{~cm}^{-1}$ for the free carboxylic group (Hunter, Thomas, de Haseth \& Wicker, 2006, Panchev, Slavov, Nikolova \& Kratchanov, 2010, Lima, Paiva, Andrade \& Paixao, 2010). There may be, however, interferences with water at $1645 \mathrm{~cm}^{-1}$. Therefore, Synytsya et al. (2003), and Fellah, Anjukandi, Waterland and Williams (2009) suggest to investigate bands around $1350-1450 \mathrm{~cm}^{-1}$ which are characteristic only for methyl groups.

In total, 8 pectin samples were examined with FT-IR before and after storage. It was expected that pectin demethoxylation after storage would decrease the ester group peak at $1750 \mathrm{~cm}^{-1}$ and increase the carboxylic group peaks at 1630 and around $1400 \mathrm{~cm}^{-1}$. The results of the 4 samples of the same supplier are shown in Fig. 3a-d. In case of the HMP (sample 2D, Fig. 3a) the results matched the hypothesis: the ester group peak was reduced and the carboxyl group peak increased after storage. The LMP-AC (sample 2 C, Fig. 3b) showed slightly reduced ester group peaks but only 
small changes at the carboxyl group peak. Despite of a considerable change in the DM, the LMPENZ (sample 2E, Fig. 3c) spectra were nearly similar prior to and after storage. The amidated pectin LMP-AMID (sample 2F, Fig. 3d) showed significant decrease at $1750 \mathrm{~cm}^{-1}$ (ester groups) but only small changes of the peaks at $1630 \mathrm{~cm}^{-1}$ and $1440 \mathrm{~cm}^{-1}$. Moreover, this sample shows two peaks at 1230 and $1650 \mathrm{~cm}^{-1}$, which are ascribed to amide groups (Engelsen \& Noorgard, 1996). The former is reduced after storage; the latter remained nearly unchanged leading to the question, whether amide groups are also influenced by storage. In summary, a test of 8 pectin samples by FT-IR in this study is not sufficient for a broader discussion; this should be examined in more detail in the future. 

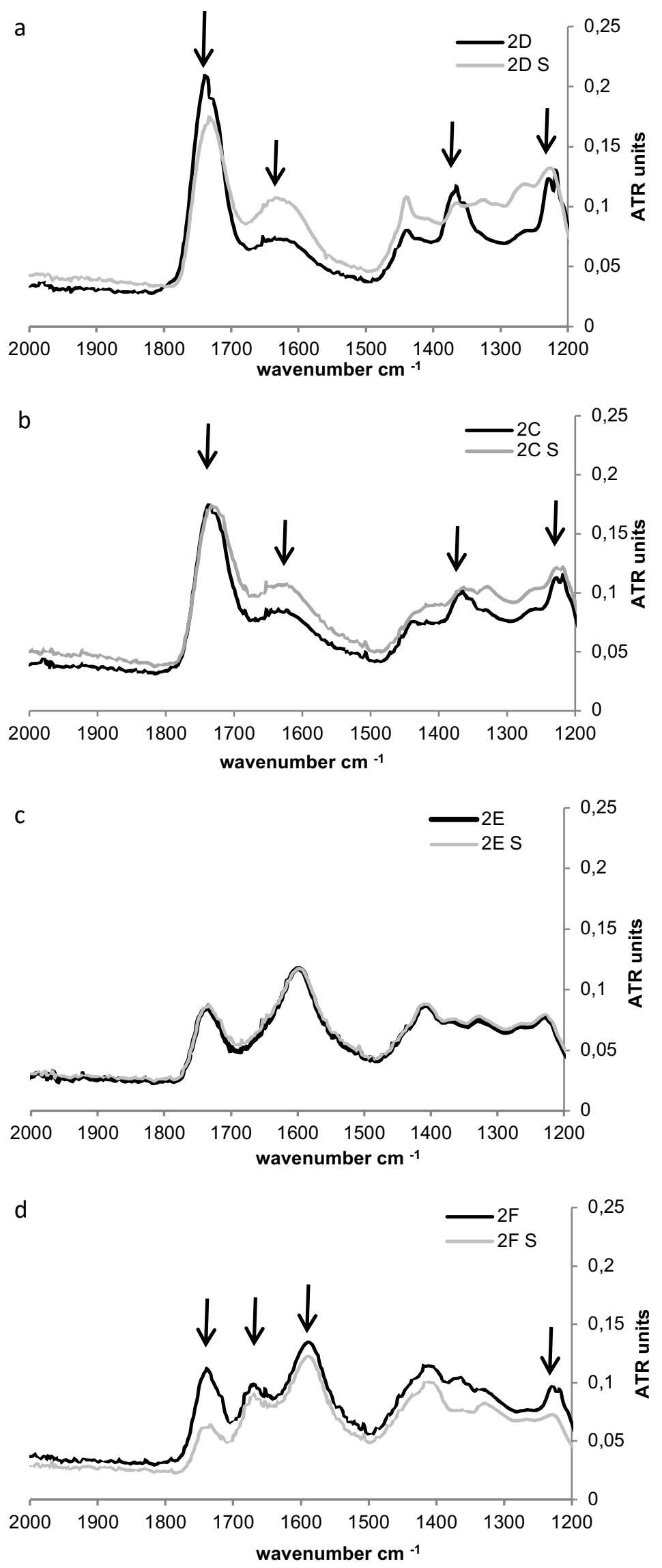

Fig. 3 FT-IR spectra of the untreated and stored pectins; $a=2 D, b=2 C, c=2 E, d=2 F$; black = untreated, grey $=$ stored pectins. 


\subsection{Changes in the colour after storage}

The colour of the original and stored pectin samples differed visibly: the powders became brown. Measurements in the L,a,b-system confirmed this with reduced values of lightness (decrease by 2 to $19 \%$ of the initial value), and an increase in red colour ( $+a)$ by 39 to $232 \%$, and in yellow colour $(+b)$ by 2 to $77 \%$ of the initial value (Table 2). The decreases of the L-value and the increases in the aand b-values differed between the samples and, thus, indicate that different reaction products with a higher intensity of red or yellow were formed during storage, respectively. Altogether, formation of red colour was dominating, the ratio of $\Delta a: \Delta b$ was $>1.00$. This is in agreement with the results of Bornik (2012), who found red coloured degradation products of pure galacturonic acid. The colour alterations of similar pectin types from different suppliers were not comparable. For instance, the stored HMP $1 \mathrm{~A}$ had an $a: b$ ratio of 1.64 and $2 \mathrm{~A}$ only 1.06 . The strong increase of $+a$ of the amidated pectin $3 \mathrm{~K}$ was not found in case of the amidated $2 \mathrm{~F}$. The details of pectin degradation and the following browning of the degradation products are not well elucidated, yet. Few publications from the 1970s and 1980s exist (Jayaraman \& van Buren, 1972, Madson \& Feather, 1979, Voragen et al., 1988) and recently lbarz et al. (2008) described an influence of galacturonic acid on the browning of fruit juices. Bornik (2012) examined the degradation of free and methoxylated galacturonic acid monomers and found a stronger colour formation during degradation of the free form. That means that demethoxylation during storage might favour also the colour formation in the stored pectins. The details of pectin browning need further investigation.

\subsection{Thermal analysis (TA)}

Thermal analysis has proved to be a good method for a relatively quick analysis of pectin alterations (Einhorn-Stoll et al., 2007, Einhorn-Stoll \& Kunzek, 2009a, 2009b) and can therefore serve as a suitable analytical tool for charactersiation of changes occurring during storage. The typical pure pectin degradation produces a big exothermic main degradation peak, sometimes accompanied by a smaller endothermic pre-peak in the DSC. As described, the DTG peaks result from changes in the sample mass; their width indicates the sample homogeneity and their height the maximum degradation velocity.

The DSC curves for pectin samples before and after storage are presented in the Figures 4-7. In general, nearly all pectin samples had broader DTG peaks after storage (increased peak width (PW), Table 2). That means they became more inhomogeneous, partly by demethoxylation, but mainly by depolymerisation. Moreover, the stored samples were degraded with a reduced maximum velocity $\left(v_{\max }\right)$, which is perhaps due to the increased inhomogeneity. Both results agree with those from the previous study on pectin samples prepared on laboratory scale (Einhorn-Stoll \& Kunzek, 2009a). The third difference between pectin samples before and after storage, a shift of the main degradation peak in DSC and DTG-curves (positive or negative $\Delta T_{P D S C}$ and $\Delta T_{P D T G}$ ), was partly 
different in model and commercial pectin. The details will be discussed separately for pectins of every type. Important results from the alterations in thermal analysis are shown in Table 2.

\subsubsection{High-methoxylated pectin samples}

The thermal analysis of the 8 HMP samples before storage (Table 1) differed already considerably and, as expected, the samples showed also a different behaviour after storage. DSC curves of some pectins (2 suppliers) changed only slightly. A small endothermic pre-peak was formed in the DSC-curves of the pectin samples from one supplier (Fig. 4b) and there were small shifts of the main degradation peaks, some to the right side (more stable, Fig. 4a) and some to the left side (less stable, Fig. 4b). Pectin samples from a third supplier showed more and different alterations. They lost their typical second small exothermic DSC peak that occurred before the main peak (Fig. 4c) and their main peak was clearly shifted to the left (less stable). Reduced thermal stability of the stored HMP samples was found also in the previous study on model pectins (Einhorn-Stoll \& Kunzek, 2009a) and was explained mainly as an effect of demethoxylation. The increased stability of the samples $1 A$ and $B$, however, is unexpected. It is likely that inter- or intramolecular bonds have been formed or transitions took place during storage, which had to be cleaved or inverted during TA before the degradation could start. 

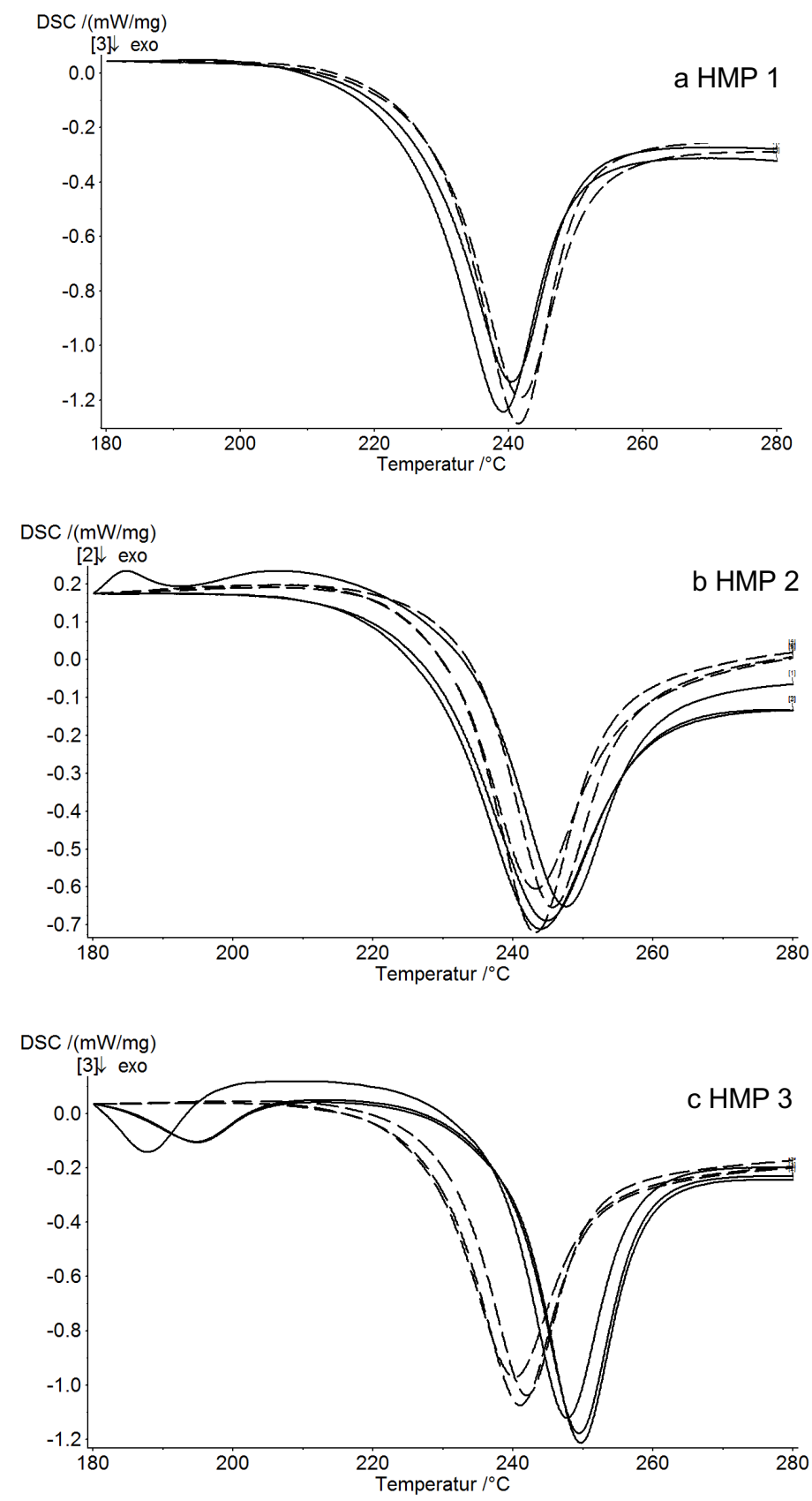

Fig. 4 Thermal analysis of HMP of different suppliers; full lines = original, dotted lines = stored pectins.

The second DSC peak in the untreated HMP in Fig. 4c might be ascribed to the degradation of neutral sugars and its loss might confirm the increasing galacturonan content by cleavage and degradation of neutral sugars as discussed above. The higher GC was found, however, also for the stored HMP in Fig. $4 a$ and $b$ that had no second DSC peaks at all. Therefore, this peak could result also from other degradations / transitions.

Nevertheless, the intensity of alterations in TA of the HMP samples mostly agreed with changes of their molecular parameters and colour. Samples with a pronounced change in GC, DM and IV after storage showed a stronger browning and stronger shifts of the DSC peaks (Table 2). 


\subsubsection{Acidic demethoxylated pectin samples LMP-AC}

Differences in the LMP-AC samples were found not only between the two suppliers but also between the samples from the same pectin producing company. The changes in TA after storage were different, too. The DSC main peaks of stored $1 \mathrm{C}$ and $2 \mathrm{C}$ shifted much stronger to the left than those of 1D (Fig. 5) and showed a newly formed or increased endothermic DSC pre-peak after storage. The shift of the main peaks to the left is in agreement with the results of the study on model pectins, even if the influence of storage on the commercial pectins was less pronounced. The increase or formation of the endothermic pre-peak after storage, however, was in sharp contrast to the results of the study on model pectins (Einhorn-Stoll \& Kunzek, 2009a). Those pre-peaks decreased or even vanished after storage. In the previous study the pre-peak had been assumed to be an indicator for a conformational transition from the ${ }^{4} C_{1}$ to the ${ }^{1} C_{4}$ form (Einhorn-Stoll \& Kunzek, 2009a). This could not be proved up to now because test methods for conformation transitions such as AFM (Marszalek et al.,1999, Marszalek, Pang, Li, Oberhauser \& Fernandez, 2002, Williams, Marshall, Anjukandi \& Haverkamp, 2007) require pectin dissolution that already alters the conformation. Whether the higher or newly formed pre-peaks in stored commercial pectin samples are indicators for an opposite transition or if they have completely different reasons, will be the subject of further investigations.
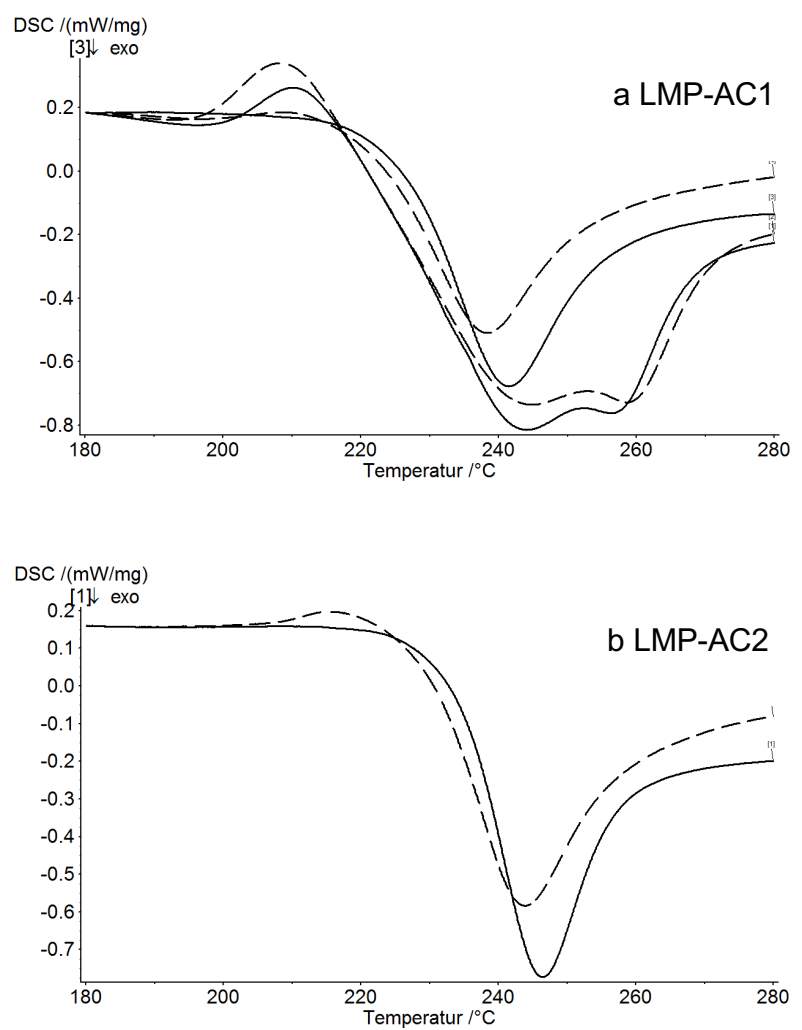

Fig. 5 Thermal analysis of LMP-AC of different suppliers; full lines = original, dotted lines = stored pectins. 


\subsubsection{Enzymatic demethoxylated pectin samples LMP-ENZ}

The untreated LMP-ENZ samples (both treated with fungal methylesterase and having random distribution of methoxyl groups) differed from the LMP-AC by a shoulder before and a small second exothermic peak after the main degradation peak in the DSC curves, they were less homogenous. After storage, the shoulder was intensified and formed an endothermic pre-peak and the second degradation peak was reduced (Fig. 6). Moreover, all main peaks of the stored pectins were shifted to the right; the samples became thermally more stable.
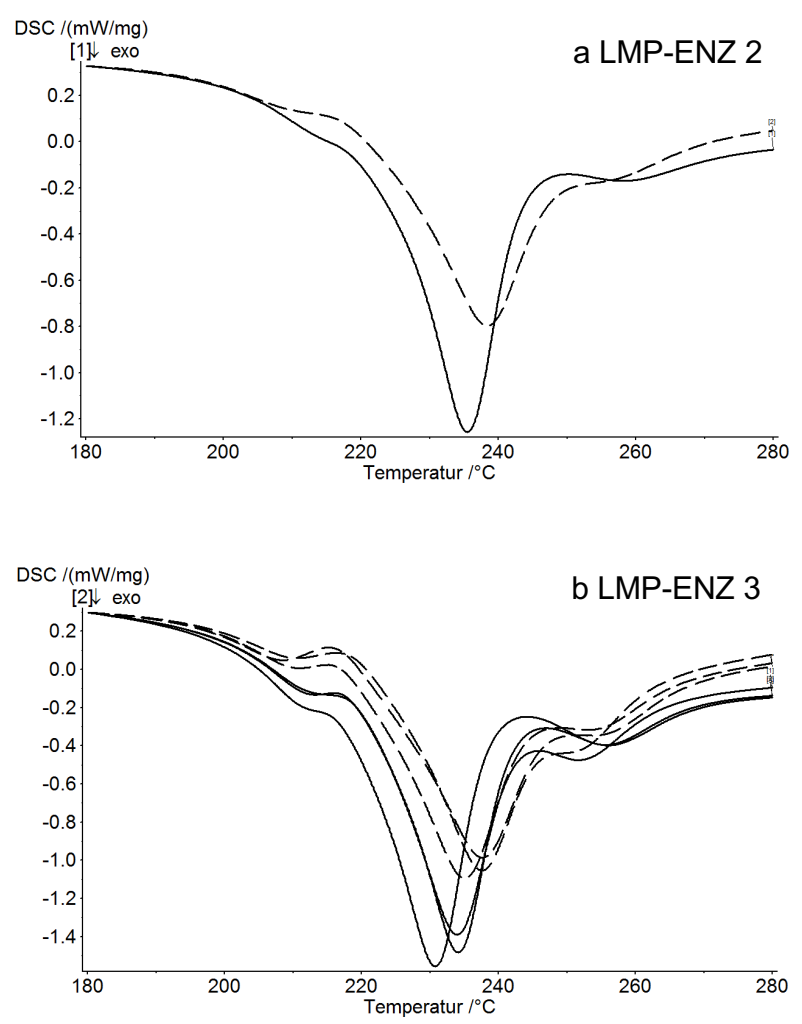

Fig. 6 Thermal analysis of LMP-ENZ of different suppliers; full lines = original, dotted lines = stored pectins.

Whereas the increased DSC pre-peaks of stored LMP-ENZ are in agreement with the results of the LMP-AC and the decrease of the second DSC degradation peaks might be explained partly with the reduction of neutral sugars, the increased thermal stability (shift of main peak to the right) is rather interesting. It seems that the type of demethoxylation (acidic or enzymatic) strongly determines the properties, and, thus, the behaviour of the commercial LMP during storage. An increased stability during thermal analysis of the stored pectins was found for no other acidic or alkaline demethoxylated LMP samples until now (Einhorn-Stoll \& Kunzek, 2009a, 2009b). 


\subsubsection{Amidated pectin samples LMP-AMID}

The behaviour of stored LMP-AMID pectin samples during thermal analysis has not been analysed before. The behaviour of the two original samples $2 \mathrm{~F}$ and $3 \mathrm{~K}$ already differed. While $2 \mathrm{~F}$ showed an endothermic DSC pre-peak (Fig. 7a), 3K only had a small shoulder, like an LMP-ENZ (Fig. 7b). Nevertheless, the influence of storage on the DSC curves of both samples was partly comparable. The DSC pre-peak as well as the shoulder increased and the main degradation peaks were only slightly influenced. The shift of the main peak was, however, to different directions. It seems that the process of amidation can cause different properties and, thus, varying effects of storage.
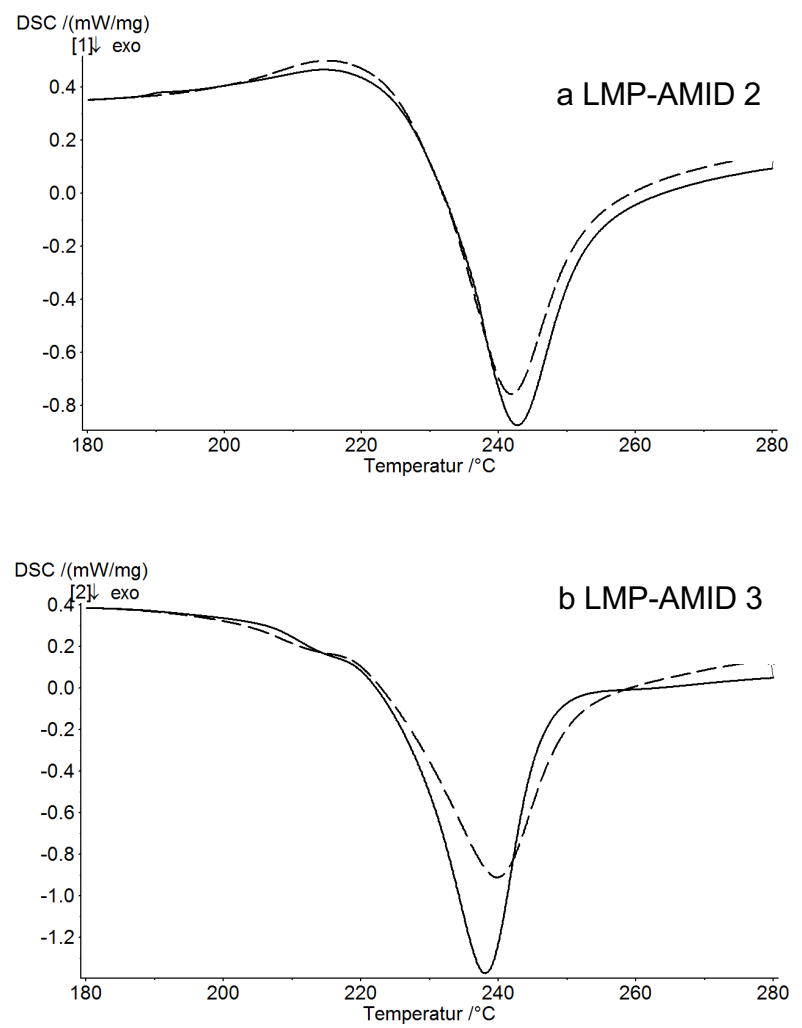

Fig. 7 Thermal analysis of LMP-AMID of different suppliers; full lines = original, dotted lines = stored pectins.

\subsection{Discussion of the different behaviour of pectin samples after storage}

The pectin samples used in the present study were obtained from different suppliers. As a consequence, it is likely that they have been prepared from different raw materials. The biological source "citrus" includes orange, lime or other citrus fruits. In addition, it can be expected that the technological conditions such as temperature, $\mathrm{pH}$, time or drying methods vary, especially in the case of the production of LMP. Therefore, already the pectin samples before storage showed different molecular parameters, such as purity, degree of methoxylation and molecular weight, as well as varying behaviour in thermal analysis (Table 1). Typical process conditions during acidic / enzymatic demethoxylation and amidation, that result in varying types, and numbers of hydrophilic groups $\left(-\mathrm{OH},-\mathrm{COOH}\right.$ and $\left.-\mathrm{NH}_{2}\right)$, are summarised in Table 3. 
Table 3 Comparison of the processing conditions during the different pectin demethoxylation procedures.

\begin{tabular}{|c|c|c|c|}
\hline \multirow[t]{2}{*}{ Modification } & Acidic demethoxylation & Enzymatic demethoxylation & Amidation \\
\hline & LMP-AC & LMP-ENZ & LMP-AMID \\
\hline $\mathrm{pH}$ & $1-3$ & $3-7$ & $>8$ \\
\hline$-\mathrm{COOH}$ groups at $\mathrm{C}_{6}$ & Mainly undissociated & Partly dissociated & Partly dissociated/amidated \\
\hline Charge & Nearly uncharged & Mainly charged & Partly charged \\
\hline Electrostatic interactions & Low repulsion & Repulsion & Repulsion \\
\hline Number hydrogen bonds & High & Low & High \\
\hline
\end{tabular}

An increase in the number of polar groups promotes water uptake and water binding (Ping, Nguyen, Chen, Zhou \& Ding, 2001) and may influence the kinetics of reactions that depend on the water activity, such as demethoxylation or depolymerisation, during storage (Padival et al., 1981). HMPs contain the lowest number of such groups and, therefore, their degradation during storage might be the least pronounced when comparing the different types of pectin. However, other factors also affect the degradation and therefore the relation is more complex. The pectin processing determines not only molecular but also structural properties, such as specific ionic or hydrophobic inter- and intramolecular interactions or specific bonds that have to be cleaved before samples can get in contact and react with water. Another factor is the accessibility of the polar groups (Matveev, Grinberg \& Tolstogusov, 2000, Lewicki, 2004), that is influenced by the material properties of the samples. Varying processing conditions can cause also different material properties such as particle size, surface morphology and porosity as previously shown for pectin samples prepared on laboratory scale (Einhorn-Stoll \& Kunzek, 2009a, Einhorn-Stoll, Hatakeyama \& Hatakeyama, 2012). These material properties affect moisture sorption and thus can promote or inhibit chemical reactions during storage which depend on the water activity.

Scanning electron microscopy can be used for a qualitative description of the pectin particles. Typical examples of the surface morphology for different types of pectins are shown in Fig. 8a-d. Though all these samples are from one supplier, they are typical examples for the according pectin type. The HMP particles (Fig. 8a) varied strongly in size; in addition, HMP samples can contain filamentous parts and have a rather porous surface. Acidic treated pectin particles (Fig. 8b) in average are larger than HMP particles and showed a much smoother surface. At first sight, enzymatically demethoxylated pectins (Fig. 8c) were comparable to LMP-AC in size but a bit more branched. Particles of amidated pectins (Fig. 8d) are more similar to HMP samples. Whereas the pectin particle size can be influenced by the milling process, the particle and surface morphology is more dependent on inter- and intramolecular interactions of the pectin molecules and is affected by process conditions. The influence of the material properties of the examined pectin samples before storage, especially particle and surface morphology, on the reactions during storage is considerable, as the different changes of their properties show. 

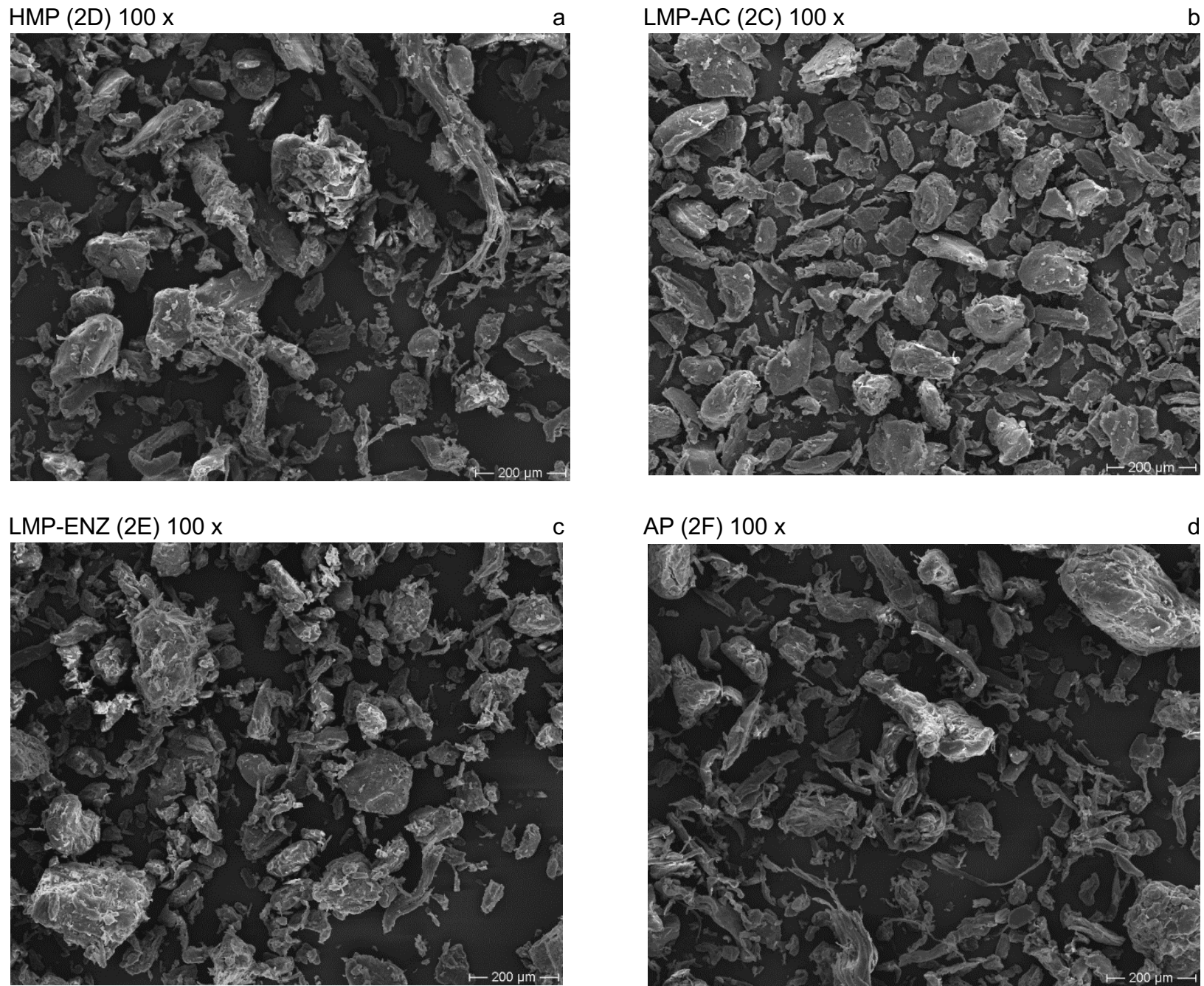

Fig. 8 Scanning electron microscopy of dry pectin particles, magnification 100; $a=H M P, b=L M P-A C, c=L M P-E N Z$, $d=L M P-A M I D$.

Small irregular, amorphous and porous particles with a high number of rapidly available polar groups can accelerate water uptake and, thus, reactions with water. Bigger and smoother amorphous particles show a slower rate of moisture sorption and, thus, the degradation process can be retarded in these particles, even if the pectin sample contains a high number of polar groups (Einhorn-Stoll et al, 2012b). 


\section{Conclusions}

A comparison of the results of the present study on commercial pectin samples with pectin samples prepared under laboratory conditions in a previous study reveals strong similarities in terms of the general mechanisms of pectin degradation, but also distinct differences between pectin types and individual pectins. In both studies the storage of pectin samples at high temperature and humidity caused thermal induced degradation of neutral sugars (increased GC), demethoxylation (reduced DM) and backbone depolymerisation (lower IV). Coloured degradation products were formed and caused browning of the pectin samples.

TA as combination of DSC and TG has proved to be a valuable instrument for detection of differences in stored pectins. Similar results of the thermal analysis in both studies are reduced homogeneity and maximum degradation velocity in pectin samples after storage (DTG-peaks). However, also two important differences became obvious: The first is the formation or an increase of endothermic pre-peaks in DSC curves of stored commercial pectin samples, while the corresponding peaks in model pectins decreased or vanished. The second difference is that in commercial pectins not only a decrease in the thermal stability (shift of the main degradation peak to the left), but also an increased stability (shift to the right) occurred. This phenomenon cannot be explained up to now. The differences are most likely caused by variations in the raw material and processing conditions between laboratory and industry or between the pectin suppliers, respectively. For instance, the $\mathrm{pH}$ can influence the pectin chain interactions prior to drying and different temperatures and methods of drying can cause varying particle and surface morphology. This will be the subject of further investigations with other methods such as solid density or surface area by BET method.

With respect to the functionality, the degradation of neutral sugars, demethoxylation and depolymerisation of the backbone can cause severe changes in the colour and the technofunctionality like structure formation during gelation. Even if the applied conditions are far from normal storage, a rapid and reliable screening method for possible alterations of pectins after storage of about six months might be of some practical relevance for pectin producing and applying companies. Though the FT-IR results were only partly satisfying, it should be tested whether there are other peaks in the IR signal that could be applied for the purpose. Relatively simple colour measurement with the $L, a, b$ system can give first information about possible changes of other properties. Also single DSC without TG might be helpful for the screening of alterations of pectins after storage. In case of a visible browning (clear increase of $a$ or b) and / or a shift of the main DSC degradation peak, it is recommended to determine the degree of methoxylation. In case the DM is strongly reduced, this should be considered during pectin application by modifying the gelling procedure and conditions ( $\mathrm{pH}$, ionic strength, sugar content, possibly addition of calcium ions). 


\section{Acknowledgements}

The authors would like to thank Astrid Kliegel for the skilful assistance in the analysis of molecular parameters and DSC measurements, Oliver Goerke for the FT-IR spectrosopy measurements and especially Herbert Kunzek for fruitful discussions and valuable advice. 
List of special abbreviations

\begin{tabular}{|c|c|}
\hline CST & critical structuring temperature \\
\hline $\mathrm{dG}^{\prime} / \mathrm{dt}$ & first derivation of $G^{\prime}=$ structure formation velocity \\
\hline $\mathrm{DM}$ & degree of methoxylation \\
\hline DSC & differential scanning calorimetry \\
\hline DTG & differential thermogravimetry \\
\hline FT-IR & Fourier-Transformation infrared spectroscopy \\
\hline$G^{\prime}$ & storage modulus \\
\hline$G^{\prime \prime}$ & loss modulus \\
\hline GP & gel point \\
\hline GC & galacturonan content \\
\hline HMP & high-methoxylated pectin \\
\hline IST & initial structuring temperature \\
\hline IV & intrinsic viscosity \\
\hline $\mathrm{L}$ & lightness \\
\hline LMP & low-methoxylated pectin \\
\hline LMP-AC & acidic demethoxylated pectin \\
\hline LMP-ENZ & enzymatic demethoxylated pectin \\
\hline LMP-AMID & amidated pectin \\
\hline O & untreated \\
\hline PW & peak width \\
\hline $\mathrm{RH}$ & relative humidity \\
\hline$S$ & stored \\
\hline SEM & scanning electron microscopy \\
\hline$T_{p}$ & peak temperature of the DSC or DTG signal \\
\hline$\Delta \mathrm{T}$ & peak broadening \\
\hline TA & thermal analysis \\
\hline TG & thermogravimetry \\
\hline$v_{\max }$ & maximum degradation velocity \\
\hline$+a$ & red colour \\
\hline$+b$ & yellow colour \\
\hline
\end{tabular}




\section{References}

Baeuerle, D., Otterbach, G., Gierschner, K. \& Baumann, G. (1977). Bestimmungen des Polyuronidgehaltes und des Veresterungsgrades des Pectinanteiles in Handelspektinpräparaten, Apfelsäften und Apfelmaceraten. Dtsch. Lebensm. Rundschau, 73, 281-286.

Blumenkrantz, N. \& Asboe-Hansen, G. (1973). New method for quantitative determination of uronic acids. Analytical Biochemistry, 54, 484-489.

Bornik, M.-A. (2012). D-Galacturonsäure in der nicht-enzymatischen Bräunungsreaktion. PhD Thesis Technische Universität Berlin.

Diaz, J.V., Anthon, G.E. \& Barrett, D.M. (2007). Nonenzymatic degradation of citrus pectin and pectate during prolonged heating: Effects of $\mathrm{pH}$, temperature and degree of methyl esterification. J. Agric. Food Chem., 55, 5131-5136.

Einhorn-Stoll, U., Salazar, T., Jaafar, B. \& Kunzek, H. (2001). Thermodynamic compatibility of sodium caseinate with different pectins. Influence of the milieu conditions and pectin modifications. Nahrung/Food, 45, 334-337.

Einhorn-Stoll, U., Kunzek, H. \& Dongowski, G. (2007). Thermal analysis of chemically and mechanically modified pectins. Food Hydrocolloids, 21, 1101-1112.

Einhorn-Stoll, U. \& Kunzek, H. (2009a). The influence of the storage conditions heat and humidity on conformation, state transitions and degradation behaviour of dried pectins. Food Hydrocolloids, 23, 856-866.

Einhorn-Stoll, U. \& Kunzek, H. (2009b). Thermoanalytical characterisation of processing-dependent structural changes and state transitions of citrus pectin. Food Hydrocolloids, 23, 40-52.

Einhorn-Stoll, U., Kastner, H. \& Senge, B. (2012). Comparison of molecular parameters, material properies and gelling behaviour of commercial citrus pectins. In P.A. Williams \& G.O. Phillips (Eds.), Gums and Stabilisers for the Food Industry 16 (pp.199-206). Cambridge, U.K.: Royal Society of Chemistry, RSC Special Publication No. 335.

Einhorn-Stoll, U., Hatakeyama, H. \& Hatakeyama, T. (2012). Influence of pectin modification on water binding properties. Food Hydrocolloids, 27, 494-502.

Engelsen, S.B. \& Norgaard, L. (1996). Comparative vibrational spectroscopy for determination of quality parameters in amidated pectins aas evaluated by chemometrics. Carbohydrate Polymers, 30, 9-24. 
Fellah, A., Anjukandi, P, Waterland, M.R. \& Williams, M.A.K. (2009). Determining the degree of methylesterification on pectin by ATR/FT-IR: Methodology optimisation and comparison with theoretical calculations. Carbohydrate Polymers, 78, 847-853.

Fraeye, I., de Roeck, A., Duvetter, T., Verlent, I., Hendrickx, M. \& van Loey, A. (2007). Influence of pectin properties and processing conditions on thermal pectin degradation. Food Chem., 105, 555-563.

Gloyna, D. \& Kunzek. H. (1998). Thermal solid phase degradation of plant cell wall polysaccharides. Polish Journal of Food and Nutrition Science, 48, 55-60.

Hunter, J.L., Thomas, A.G.A., de Haseth, J.A. \& Wicker, L. (2006). Valencia orange pectinmethylesterase modified pectin characterized by Fourier Transform infrared spectroscopy, charge fractionation and gelling. Journal of Food Quality, 29, 479-491.

Ibarz, A. Pagan, A. Tribaldo, F. \& Pagan, J. (2006). Improvement in the measurement of spectrophotometric data in the m-hydroxydiphenyl pectin determination methods. Food Control, $17,890-893$

Ibarz, A., Garza, S. \& Pagán, J. (2008). Nonenzymatic browning of selected fruit juices affected by D-galacturonic acid. International Journal of Food Science and Technology, 43, 908-914.

Jayaraman, A. \& van Buren, J.P. (1972). Browning of glacturonic acid in a model system simulating fruit beverages and white wine. Journal of Agricultural and Food Chemistry, 20, 122-124.

Kastner, H., Einhorn-Stoll, U. \& Senge, B. (2012a). New parameters fort he examination of the pectin gelation process. In P.A. Williams \& G.O. Phillips (Eds.), Gums and Stabilisers for the Food Industry 16 (pp.199-206). Cambridge, U.K.: Royal Society of Chemistry, RSC Special Publication No. 335.

Kastner, H., Einhorn-Stoll, U. \& Senge, B. (2012b). Structure formation in sugar containing pectin gels - Influence of $\mathrm{Ca} 2+$ on the gelation of low-methoxylated pectin at acidic $\mathrm{pH}$. Food Hydrocolloids, 27, 42-49.

Keijbets, M.H. \& Pilnik, W. (1974). ß-Elimination of pectin in the presence of anions and cations. Carbohydrate Res., 33, 359-362.

Krall, S.M. \& McFeeters, R.F. (1998). Pectin hydrolysis: Effect of temperature, degree of methylation, $\mathrm{pH}$ and calcium on hydrolysis rates. J. Agric. Food Chem., 6, 1311-1315.

Kravtchenko, T.P., Arnould, I., Voragen, A.G.J. \& Pilnik, W. (1992). Improvement of the selective depolymerization of pectic substances by chemical ß-elimination in aqueous solution. Carbohydrate Polymers, 19, 237-242. 
Lewicki, P.P. (2004). Water as the determinant of food engineering properties. A review. J. Food Engineering, 61, 483-495.

Lima, M.S., Paiva, E.P., Andrade, S.A.C. \& Paixao, J.A. (2010). Fruit pectins - A suitable tool for screening gelling properties using infrared spectroscopy. Food Hydrocolloids, 24, 1-7.

Lopes da Silva, J.A. \& Rao, M.A. (2006). Pectins: Structure, functionality and uses. In: A.M. Stephen, G.O. Phillips \& P.A. Williams (Eds.), Food polysaccharides and their applications. 2. edition, pp. 353-411. Ort: Verlag!!!

Madson, M.A. \& Feather, M.S. (1979). The acid-catalyzed decarboxylation of D-xyluronic, Dgalacturonid and D-glycero-D-gulo-hepturonic acid. Carbohydrate Research, 70, 307-311.

Marszalek, P.E., Pang, Y.P., Li, H. B., El Yazal, J., Oberhauser, A F. \& Fernandez, J.M. (1999). Atomic levers control pyranose ring conformations. Proc. Nat. Acad. Sci. USA, 96, 7894-7898.

Marszalek, P.E., Li, H.B., Oberhauser, A.F. \& Fernandez, J.M. (2002). Chair-boat transitions in single polysaccharide molecules observed with force-ramp AFM. Proc. Nat. Acad. Sci. USA, 99, $4278-4283$

Matveev, Y.I., Grinberg, V.Y. \& Tolstogusov, V.B. (2000). The plasticizing effect of water on proteins, polysaccharides and their mixtures. Glassy state of biopolymers, food and seeds. Food Hydrocolloids, 14, 425-437.

Padival, R.A., Ranganna, S. \& Manjrekar, S.P. (1981). Stability of pectins during storage. J. Food Technol., 16, 367-378.

Panchev, I.N., Slavov, A., Nikolova, K. \& Kovacheva, D. (2010). On the water-sorption properties of pectin. Food Hydrocolloids, 24, 763-769.

Ping, Z.H., Nguyen, Q.T., Chen, J.Q. \& Ding, Y.D. (2001). States of water in different hydrophilic polymers - DSC and FTIR studies. Polymer, 42, 8461-8467.

Rolin, C. (2002). Commercial pectin preparations. In: G.B. Seymour \& J.P. Knox (Eds.), Pectins and their Manipulation (pp. 222-241). Oxford: Blackwell Publishing.

Rolin, C., Chrestensen, I. B., Hansen, K.M., Staunstrup, J. \& Sorensen, S. (2010). In P.A. Williams \& G.O. Phillips (Eds.), Gums and Stabilisers for the Food Industry 15 (pp.13-25). Cambridge, U.K.: Royal Society of Chemistry, RSC Special Publication No. 325.

Schols, H.A. \& Voragen, A G.J. (2002). The chemical structure of pectins. In: G.B. Seymour \& J.P. Knox (Eds.), Pectins and their Manipulation (pp. 1-29). Oxford: Blackwell Publishing. 
Schols, H.A., Coenen, G.-J. \& Voragen, A.G.J. (2009). Revealing pectin's structure. In: H.A. Schols, R.G.F. Visser \& A.G.J. Voragen (Eds.), Pectins and Pectinases (pp. 19-34). Wageningen: Academic Publishers.

Synytsya, A., Copikova, J., Matejka, P. \& Machovic, V. (2003). Fourier transform Raman and infrared spectroscopy of pectins. Carbohydrate Polymers, 54, 97-106.

Thakur, B.R., Sing, R.K. \& Handa, A.K. (1997). Chemistry and uses of pectin - a review. Crit. Rev. Food Sci. Nutr., 37, 7-73.

Vincken, J.-P., Schols, H.A., Oomen, R.J.F.J., McCann, M., Ulvskov, P., Voragen, A.G.J. \& Visser, R.G.F. (2003). If homogalacturonan were a side chain of rhamnogalacturonan. I. Implication for cell wall architecture. Plant Physiology, 132, 1781-1789.

Voragen, G. J., Schols, H. A. \& Pilnik, W. (1988). Non-enzymatic browning of oligogalacturonides in apple juice models. Z. Lebensm. Unters. Forsch., 187, 315-320.

Voragen, A.G.J., Pilnik, W., Thibault, J.-F., Axelos, M.A.V. \& Renard, C.M.G. (1995). Pectins. In: A.M. Stephen (Ed.), Food Polysaccharides and their Application (pp. 287-339). New York: Marcel Dekker Inc.

Wiiliams, M.A.K., Marshall, A.T., Anjukandi, P. \& Haverkamp, R.G. (2007). Investigation of the effects of fine structure on the nanomechanical properties of pectin. Physical Review, 76, 021927, 1-8. 